\title{
SIRT1-mediated regulation of oxidative stress induced by Pseudomonas aeruginosa lipopolysaccharides in human alveolar epithelial cells
}

\author{
XIAOLI LIU ${ }^{1}$, TUO YANG ${ }^{2}$, TIEYING SUN ${ }^{3}$ and KUIQING SHAO ${ }^{4}$ \\ ${ }^{1}$ Department of Respiratory Medicine, Beijing Shijitan Hospital, Capital Medical University, Beijing 100038, P.R. China; \\ ${ }^{2}$ Department of Neurology, University of Pittsburgh, Pittsburgh, PA 15260, USA; \\ ${ }^{3}$ Department of Respiratory and Critical Care Medicine, Beijing Hospital Ministry of Health, Beijing 100730; \\ ${ }^{4}$ Department of Urinary Surgery, Xiyuan Hospital of China Academy of Chinese Medical Sciences, Beijing 100091, P.R. China
}

Received January 10, 2016; Accepted October 19, 2016

DOI: $10.3892 / \mathrm{mmr} .2016 .6045$

\begin{abstract}
Sirtuin1 (SIRT1) is an NAD+-dependent deacetylase that exhibits multiple biological functions, including cell differentiation inhibition, transcription regulation, cell cycle regulation and anti-apoptosis. Lipopolysaccharides (LPS) are crucial virulence factors produced by Pseudomonas aeruginosa and serve an important role in adjusting the interactions between the host and the pathogen. However, the effect of SIRT1 in the regulation of LPS-induced A459 human alveolar epithelial cells (AECs) oxidative stress remains unclear. The cellular reactive oxygen species (ROS) production was examined in A549 cells that were supplemented with LPS. Relative cell signaling pathway proteins were further investigated by western blot analysis. It was identified that LPS downregulated SIRT1 expression, however, upregulated ROS generation, which was associated with the increase of nuclear factor $(\mathrm{NF})-\kappa \mathrm{B}$ and acetyl-NF- $\kappa \mathrm{B}$. Activation of SIRT1 by resveratrol significantly reversed the effects of LPS on A549 cells. By contrast, inhibition of SIRT1 by nicotinamide had the opposite effects that enhance cell ROS production. Thus, the results indicated that SIRT1 serves an important role in the regulation of oxidative stress induced by LPS in human AECs.
\end{abstract}

\footnotetext{
Correspondence to: Dr Tieying Sun, Department of Respiratory and Critical Care Medicine, Beijing Hospital Ministry of Health, 1 Dahua Street, Dongcheng, Beijing 100730, P.R. China

E-mail: suntieying3@hotmail.com

Dr Kuiqing Shao, Department of Urinary Surgery, Xiyuan Hospital of China Academy of Chinese Medical Sciences, 1 Xiyuancaochang, Hadian, Beijing 100091, P.R. China

E-mail: shaokuiqing@163.com
}

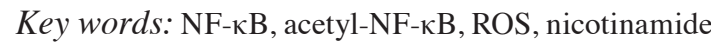

\section{Introduction}

Pseudomonas aeruginosa is one of the most prevalent opportunistic gram-negative bacteria that lead to pneumonia in immunocompromised patients through the production of numerous virulence factors, including enzymes and exotoxin, such as lipopolysaccharides (LPS) (1-5). P. aeruginosa accounts for $10-20 \%$ of all hospital-acquired infection (6), $18.1 \%$ of nosocomial pneumonia (7), 9.3\% of ventilator-associated pneumonia (8) and $0.9-1.9 \%$ of community-acquired pneumonia requiring hospitalization (9-11). LPS are the most important pathogenic factors produced by $P$. aeruginos $a$ and serve a major role in the interplay between the host and the pathogen. Type II alveolar epithelial cells (AECs) are major target cells of LPS locating in the alveolar corners, exhibiting various important functions including initiation of immune responses, fluid balance, mucus and surfactant production, and progenitor action to maintain the normal function of the alveoli (12-14).

Sirtuin1 (SIRT1), an NAD ${ }^{+}$-dependent class III protein deacetylase, belongs to the silent information regulator (Sir) family (15) and is suggested to serve diverse roles in gene silencing, stress resistance, apoptosis, senescence, aging and inflammation (16-19). Previous studies have demonstrated that SIRT1 can regulate cellular oxidative stress and its toxicity (20-23). Modulation of the acetylation of the p65 subunit of nuclear factor $\mathrm{kB}(\mathrm{NF}-\kappa \mathrm{B})$ in cells or tissues is the major means via which SIRT1 regulates cellular oxidative status (24).

At present, to the best of our knowledge, no reports have focused on the potential roles of SIRT1 in the regulation of oxidative stress induced by $P$. aeruginosa LPS in human AECs. In the current study, the effects of SIRT1 on the regulation of reactive oxidative stress, which is indicated by reactive oxygen species (ROS) generation, was examined in LPS-stimulated A549 cells.

\section{Materials and methods}

Cell culture and drug treatment. A549 cells were maintained as previously described (25). Briefly cells were maintained in 
Dulbecco's modified Eagle's medium (DMEM) F-12 culture medium (GE Healthcare Life Sciences, Logan, UT, USA) containing $10 \%$ heat-inactivated fetal calf serum, $100 \mathrm{U} / \mathrm{ml}$ penicillin, and streptomycin respectively, in $25-\mathrm{cm}^{2}$ culture flasks at $37^{\circ} \mathrm{C}$ in a humidified atmosphere with $5 \% \mathrm{CO}_{2}$. LPS (Sigma-Aldrich; Merck Millipore, Darmstadt, Germany) was dissolved in sterilized phosphate-buffered saline (PBS). Cells were pretreated with nicotinamide (NAM) and resveratrol [Res; dissolved in dimethyl sulfoxide (DMSO); all from Sigma-Aldrich; Merck Millipore) for $1 \mathrm{~h}$ prior to LPS stimulation. The concentration of DMSO in the medium never exceeded $0.1 \%$ to avoid the toxicity of this solvent towards the A549 cells. Cells were divided into four groups, including a DMSO group (control), a Res group, a LPS treatment plus DMSO group (DMSO+LPS), and a LPS-treated Res group (Res+LPS).

Fluorescence staining. A549 cells were cultured on six-well chamber slides and were washed with PBS three times for 5 min per wash, then subsequently incubated with ROS Fluorescent Probe-DHE (Vigorous Biotechnology Beijing Co., Ltd., Beijing, China) in serum-free DMEM F-12 medium for $30 \mathrm{~min}$ at $37^{\circ} \mathrm{C}$ in darkness and fixed in $4 \%$ paraformaldehyde for $30 \mathrm{~min}$ at room temperature. The slides were washed again and mounted. The slides were finally examined using a fluorescence microscope.

Quantification of intracellular ROS. Intracellular ROS levels were quantified using ROS Fluorescent Probe-Dihydroethidium (DHE) to determine the oxidative stress towards the A549 cells in response to LPS stimulation. Following drug treatment, A549 cells were treated with dichlorofluorescin diacetate, a ROS-sensitive dye, and incubated for $30 \mathrm{~min}$ at $37^{\circ} \mathrm{C}$ in a humidified and dark atmosphere. A549 cells were harvested and suspended in PBS $(0.14 \mathrm{M} \mathrm{NaCl}, 2.6 \mathrm{mM} \mathrm{KCl}, 8 \mathrm{mM}$ $\mathrm{Na}_{2} \mathrm{HPO}_{4}$, and $1.5 \mathrm{mM} \mathrm{KH}_{2} \mathrm{PO}_{4}$ ). Relative fluorescence intensities in the A549 cells were analyzed with flow cytometry (BD Biosciences, Franklin Lakes, NJ, USA).

Protein extraction and western blotting analysis. Following treatments, the cells were washed with ice-cold PBS three times. Proteins were extracted from the A549 cells in radioimmunoprecipitation assay buffer [ $1 \%$ Triton X-100, $150 \mathrm{mmol} / \mathrm{l}$ $\mathrm{NaCl}, 5 \mathrm{mmol} / \mathrm{l}$ EDTA and $10 \mathrm{mmol} / \mathrm{l}$ Tris-HCl (pH 7.0)] containing a protease inhibitor cocktail. Following sonication, cell lysates were subjected to centrifugation at 12,000 $\mathrm{x} g$ at $4^{\circ} \mathrm{C}$ for $15 \mathrm{~min}$ and the supernatants were collected as the total protein. Total protein (10-50 $\mu \mathrm{g} / \mathrm{lane})$ was electrophoresed and separated on a 10\% SDS-polyacrylamide gel and transferred to a polyvinylidene difluoride membrane (EMD Millipore, Billerica, MA, USA), which was then soaked in $8 \%$ non-fat milk in Tris-buffered saline with $1 \%$ Tween-20 (TBST; $\mathrm{pH}$ 7.6) at room temperature for $2 \mathrm{~h}$ to block non-specific binding sites. The membranes were then incubated at $4^{\circ} \mathrm{C}$ overnight with a rabbit SIRT1 polyclonal antibody (EMD Millipore; cat. no. 07-131) at a dilution of 1:3,000, a rabbit NF- $\kappa B$ polyclonal antibody (Santa Cruz Biotechnology, Inc., Dallas, TX, USA; cat. no. sc-7178) at a dilution of 1:1,000 or a rabbit acetyl-NF- $\mathrm{KB}$ polyclonal antibody (Cell Signaling Technology, Inc., Danvers, MA, USA; cat. no. 3045) at a dilution of 1:1,000 on a rotating platform at $4^{\circ} \mathrm{C}$. Subsequently, the membrane was rinsed in TBST (pH 7.6) 3 times and incubated with horseradish peroxidase-conjugated $\operatorname{IgG}$ antibodies diluted in TBST (1:5,000; Abmart, Inc., Shanghai, China; cat. no. M21003) for $2 \mathrm{~h}$ on a rotating platform at room temperature. Bands were visualized using a horseradish peroxidase developer, and background-subtracted signals were quantified on a laser densitometer (Bio-Rad Laboratories, Inc., Hercules, CA, USA). A $\beta$-actin antibody (Santa Cruz Biotechnology, Inc.) was used to normalize the signal obtained for the total protein extracts. The protein bands were quantified using a PhosphorImager and ImageQuant (GE Healthcare Life Sciences) software analysis.

Statistical analysis. Data are expressed as the mean \pm standard error of the mean. Multiple comparisons were evaluated by one-way analysis of variance followed by Tukey's multiple-comparison test. $\mathrm{P}<0.05$ was considered to indicate a statistically significant difference.

\section{Results}

SIRT1 expression was reduced and ROS generation was elevated by LPS in A549 cells. In order to investigate the associations between ROS and SIRT1, the effects of LPS on SIRT1 protein expression and the generation of intracellular ROS following LPS treatment were assessed. A549 cells were treated with $10 \mu \mathrm{g} / \mathrm{ml}$ LPS for 12,24 or $48 \mathrm{~h}$ or with $0.1,1$, or $10 \mu \mathrm{g} / \mathrm{ml}$ LPS for $48 \mathrm{~h}$. Western blotting indicated that when the A549 cells were treated with $10 \mu \mathrm{g} / \mathrm{ml}$ LPS for $48 \mathrm{~h}$, SIRT1 protein expression was reduced by $50 \%$ (Fig. 1A). LPS significantly reduced the level of SIRT1 expression in a dose-dependent manner. At doses of 1 and $10 \mu \mathrm{g} / \mathrm{ml}$, the SIRT1 protein expression was downregulated to 28 and $51 \%$ compared with the control group, respectively (Fig. 1B). In addition, the generation of intracellular ROS was investigated. The results demonstrated that LPS elevated the generation of intracellular ROS in a time-dependent manner. At the $48 \mathrm{~h}$ time point, the generation of ROS was increased by approximately three times.

SIR1 regulates LPS-induced A549 cell ROS generation associated with the activation of $N F-\mathrm{kB}$ pathway. In order to determine the level of oxidative stress induced by LPS, cells were treated with $10 \mu \mathrm{g} / \mathrm{ml}$ LPS for $48 \mathrm{~h}$. Fluorescence staining illustrated that A549 cells incubated with LPS had increased ROS generation (Fig. 2A). Subsequently, the molecular mechanisms involved in A549 cell oxidative stress induced by LPS were investigated. Through 48-h LPS exposure, it was identified that LPS reduced SIRT1 protein expression and promoted NF- $\mathrm{KB}$ protein expression and NF- $\mathrm{KB}$ protein acetylation (Fig. 2B).

A549 cell oxidative stress is attenuated by Res through the

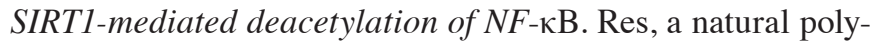
phenol compound widely found in grapes, pine trees, peanuts and other plants and fruits, has comprehensive biochemical and physiological functions, including anti-cancer, anti-inflammatory and anti-oxidant activities, that regulate lipid actions (26-31). Res is widely accepted to activate SIRT1, thus, is frequently adopted as a SIRT1 enhancer. In order to 
A

SIRT

$\beta$-actin

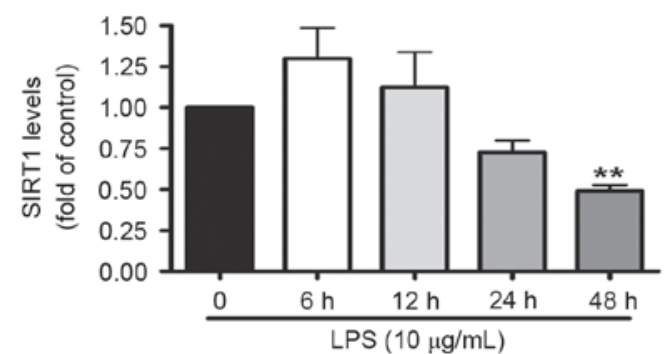

B
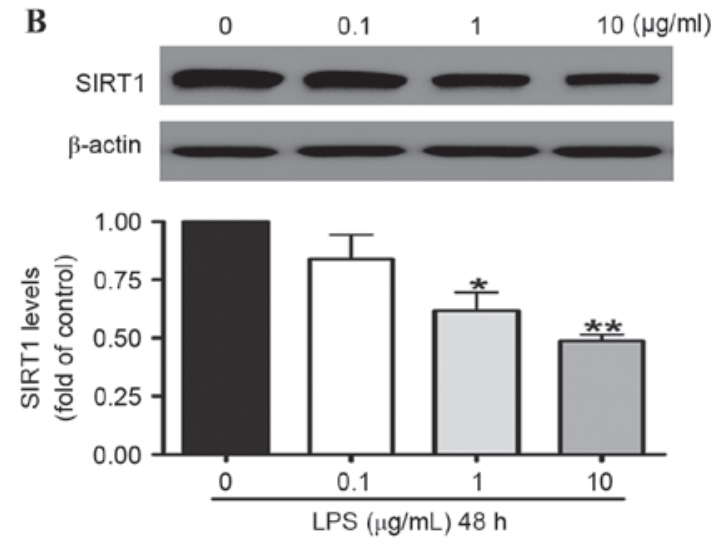

C

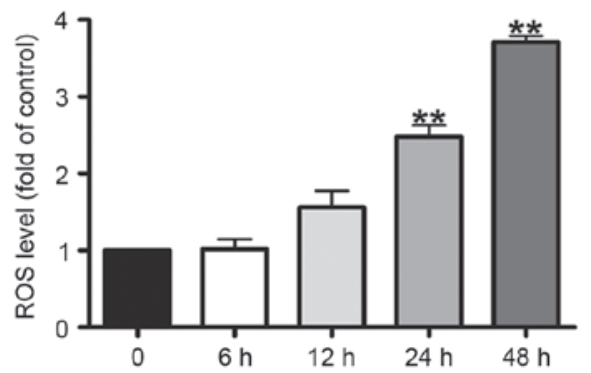

Figure 1. SIRT1 protein expression was reduced by LPS in the A549 cells. A549 cells were exposed to $10 \mu \mathrm{g} / \mathrm{ml}$ LPS for (A) $6,12,24$ or $48 \mathrm{~h}$ or (B) $0.1,1$ or $10 \mu \mathrm{g} / \mathrm{ml}$ LPS for $48 \mathrm{~h}$. Western blotting illustrated that SIRT1 protein expression in the A549 cells was reduced significantly at $48 \mathrm{~h}$ (A), and was reduced by LPS in the A549 cells in a dose-dependen manner (B). (C) A549 cells were treated with $10 \mu \mathrm{g} / \mathrm{ml}$ LPS for 6, 12, 24 and $48 \mathrm{~h}$. Levels of intracellular ROS in the A549 cells were quantified using flow cytometry. ROS generation was increased by LPS in the A549 cells in a time-dependent manner. Data are presented as the mean \pm standard error, $\mathrm{n}=3$ independent experiments. ${ }^{*} \mathrm{P}<0.05,{ }^{* *} \mathrm{P}<0.01$ vs. control. SIRT1, sirtuin 1 ; LPS, lipopolysaccharides.

determine the pivotal role of SIRT1 in regulating A549 cell oxidative stress induced by LPS, the cells were divided into four groups, including a DMSO group (control), a Res group, a LPS treatment plus DMSO group (DMSO+LPS), and a LPS-treated Res group (Res+LPS). The results suggested that Res induces SIRT1 protein expression in A549 cells in a dose-dependent manner. At doses of 5 and $20 \mu \mathrm{M}$, the increases in SIRT1 protein expression reached $58 \%$ and $91 \%$, respectively (Fig. 3A). According to the results above, $20 \mu \mathrm{M}$ was selected as the dose used in the subsequent experiments. It was demonstrated that ROS generation was reduced by Res in the A549 cells (Fig. 3C). The effects of Res on the activation of the SIRT1 pathways were partially reversed by
A

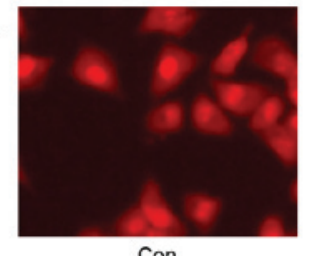

Con

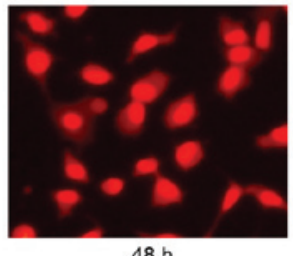

B
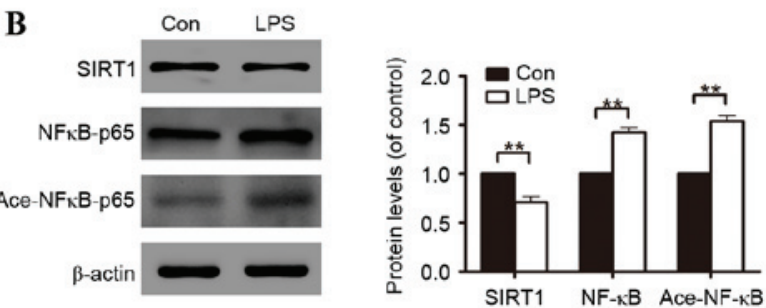

Figure 2. SIRT1 and NF- $\mathrm{NB}$ regulate the A549 cell oxidative stress induced by LPS. (A) A549 cells were treated with $10 \mu \mathrm{g} / \mathrm{ml} \mathrm{LPS} \mathrm{for} 48 \mathrm{~h}$ and were stained with ROS Fluorescent Probe-Dihydroethidium to indicate levels of ROS (magnification, x200). (B) Western blotting illustrated that LPS reduces SIRT1 protein expression and stimulates the level of acetylated NF- $\kappa$ B. Data are presented as the mean \pm standard error, $n=3$ independent experiments ${ }^{* *} \mathrm{P}<0.01$ vs. control. SIRT1, sirtuin 1 ; NF- $\mathrm{B}$, nuclear factor $\kappa \mathrm{B}$; ROS, reactive oxygen species; Con, control; LPS, lipopolysaccharides; Ace-NF- $\kappa \mathrm{B}$, acetyl- NF- $\kappa \mathrm{B}$.

LPS-stimulated downregulation of NF- $\kappa \mathrm{B}$ deacetylation in the A549 cells (Fig. 3B).

NAM aggravates LPS-induced A549 cell oxidative stress by inhibiting the SIRT1 pathway. To further determine the role of SIRT1 in regulating the human alveolar epithelial A549 cell oxidative stress induced by LPS, NAM was selected as an inhibitor of SIRT1. The results illustrated that SIRT1 protein expression in the A549 cells was reduced by NAM in a dose-dependent manner. At doses of 5 and $10 \mathrm{mmol} / \mathrm{ml}$, the reductions in SIRT1 protein expression were 27 and 51\%, respectively (Fig. 4A). The ROS generation was examined in the A549 cells, indicating that the ROS generation in the A549 cells was increased (Fig. 4C). The effects of LPS on the inhibition of the SIRT1 pathway were aggravated by NAM in the A549 cells (Fig. 4B).

\section{Discussion}

P.aeruginosa is a conditional Gram-negative bacterium leading to pneumonia in immunosuppressed patients and is colonized in the lower respiratory tract of patients with primary pulmonary diseases. In addition, ventilated patients are particularly susceptible to developing $P$. aeruginosa pneumonia $(32,33)$. The mortality of ventilator-associated pneumonia due to $P$. aeruginosa has been observed to be significantly higher than that of other pathogens (34). LPS is one of predominant virulence factors produced by $P$. aeruginosa. The current study clarified the role of SIRT1 in regulating oxidative stress induced by $P$. aeruginosa LPS in human alveolar epithelial A549 cells.

Few studies have elucidated the association between SIRT1 and $P$. aeruginosa pneumonia-induced lung injury. The present study demonstrated SIRT1 expression had been significantly reduced in A549 cells that had been treated with 
A
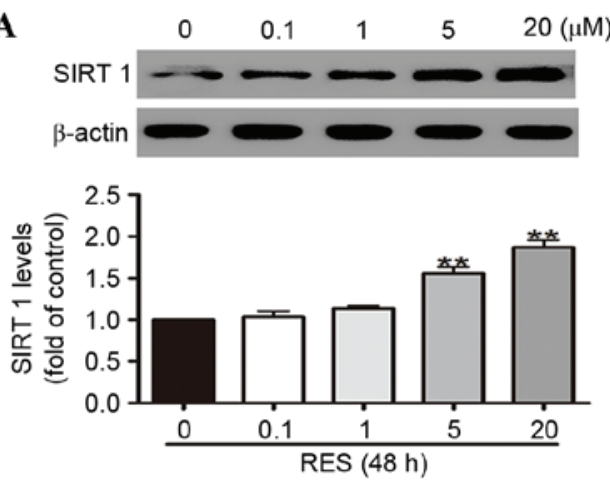

B
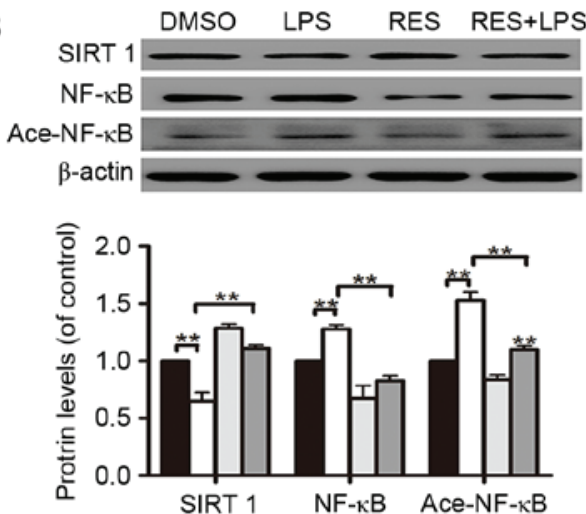

C

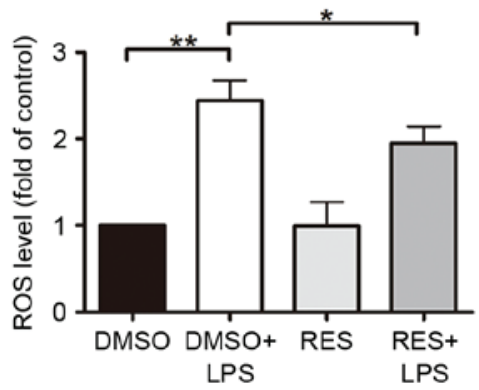

Figure 3. A549 cell oxidative stress is attenuated by Res through the SIRT1-mediated deacetylation of NF-kB. A549 cells were exposed to $0.1,1$, 5 and $20 \mu \mathrm{M}$ Res for $48 \mathrm{~h}$. (A) Western blotting illustrated that SIRT1 protein expression was increased by Res in the A549 cells in a dose-dependent manner. (B) The effects of Res on the activation of the SIRT1 pathways were partially reversed by LPS via NF- $\kappa$ B deacetylation in the A549 cells. (C) Res reduces ROS generation in A549 cells. Data are presented as the mean \pm standard error, $\mathrm{n}=3$ independent experiments. ${ }^{*} \mathrm{P}<0.05,{ }^{* *} \mathrm{P}<0.01$ vs. control. Res, resveratrol; SIRT1, sirtuin 1; NF- $\mathrm{B}$, nuclear factor $\kappa \mathrm{B}$; LPS, lipopolysac-

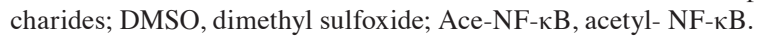

LPS, in a dose-dependent manner. Following $48 \mathrm{~h}$ stimulation, the expression of SIRT1 was significantly reduced. Previous studies have reported that LPS increases the generation of reactive oxygen species in lungs, leading to lung damage $(35,36)$. The results of the current study suggested that the generation of ROS was elevated in the A549 cells in a time-dependent manner following exposure to LPS, which is consistent with previous studies (37-40). Accordingly, it was hypothesized that the possible mechanisms of $P$. aeruginosa-induced lung damage may be associated with reactive oxidative stress in the alveolar type II epithelial cells induced by LPS.

SIRT1 is a NAM adenine dinucleotide (NAD+)-dependent histone deacetylase involved in multiple cellular functions $(41,42)$. Previous studies have elucidated that SIRT1 serves an important role in oxidative stress (43-48). In
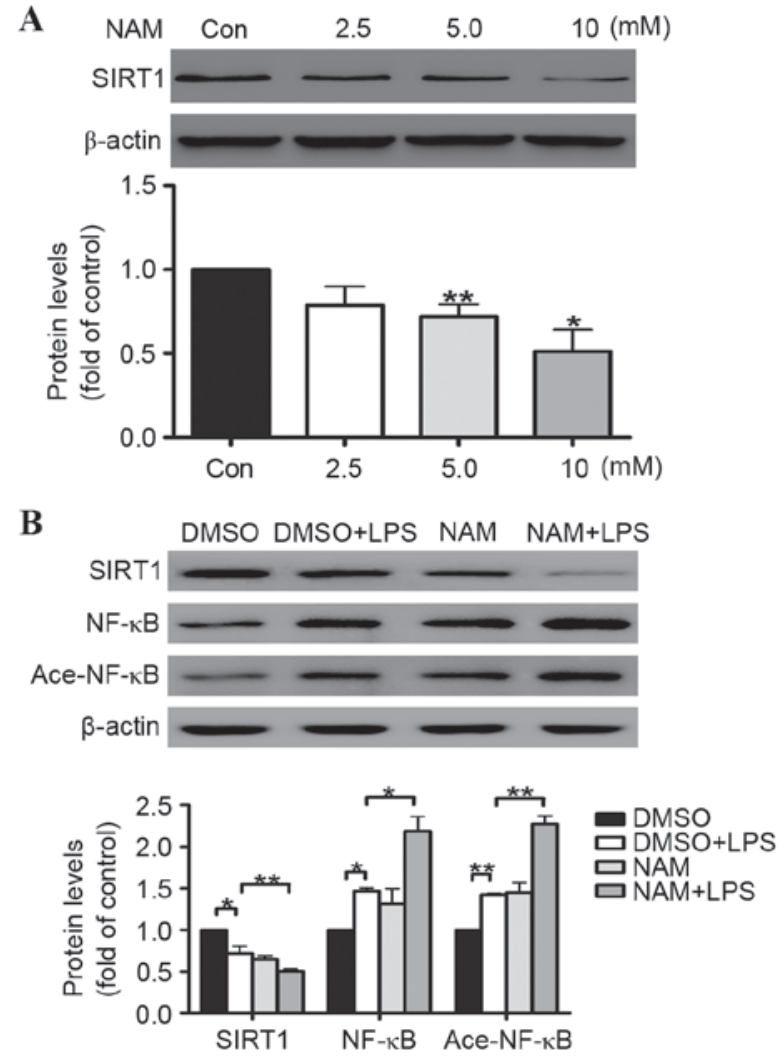

C

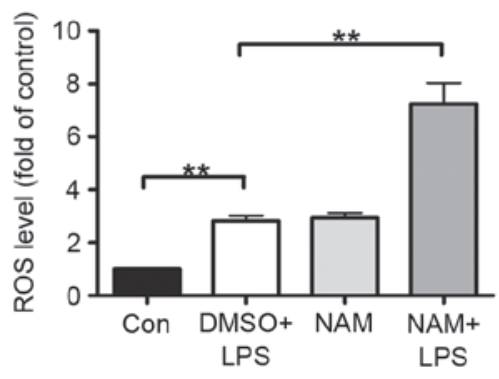

Figure 4. NAM aggravates LPS-induced A549 cell oxidative stress by inhibiting the SIRT1 pathway. A549 cells were exposed to $2.5,5$ or 10 mM NAM for $48 \mathrm{~h}$. (A) Western blotting illustrated that SIRT1 protein expression was reduced in the A549 cells in a dose-dependent manner. (B) The effect of LPS on the inhibition of the SIRT1 pathways was aggravated by NAM in the A549 cells. (C) NAM increases ROS generation in A549 cells. Data are presented as the mean \pm standard error, $\mathrm{n}=3$ independent experiments. ${ }^{*} \mathrm{P}<0.05,{ }^{* * *} \mathrm{P}<0.01$ vs. control. NAM, nicotinamide; LPS, lipopolysaccharides; SIRT1, sirtuin 1; ROS, reactive oxygen species; Con, control; DMSO, dimethyl sulfoxide.

addition, SIRT1 participates in adjusting the inflammatory response through modulation of the acetylation status of the p65 subunit of NF- $\kappa \mathrm{B}$, which is activated by oxidative stress (24). However, it is not currently clear whether SIRT1 is inhibited or activated under oxidative stress. In the current study, SIRT1 expression was reduced during the process of LPS-induced A549 cell oxidative stress, associated with upregulation of NF- $\kappa \mathrm{B}$ and acetylation of NF- $\mathrm{BB}$. This indicates that SIRT1 serves a crucial inhibitory role during the process of A549 cell oxidative stress induced by LPS through regulating the NF- $\mathrm{\kappa B}$ signaling pathway. Therefore, reductions in SIRT1 expression induced by LPS may be associated with lung injury.

To further verify the pivotal role of SIRT1 in LPS-induced oxidative stress, a SIRT1 activator and inhibitor were used to 


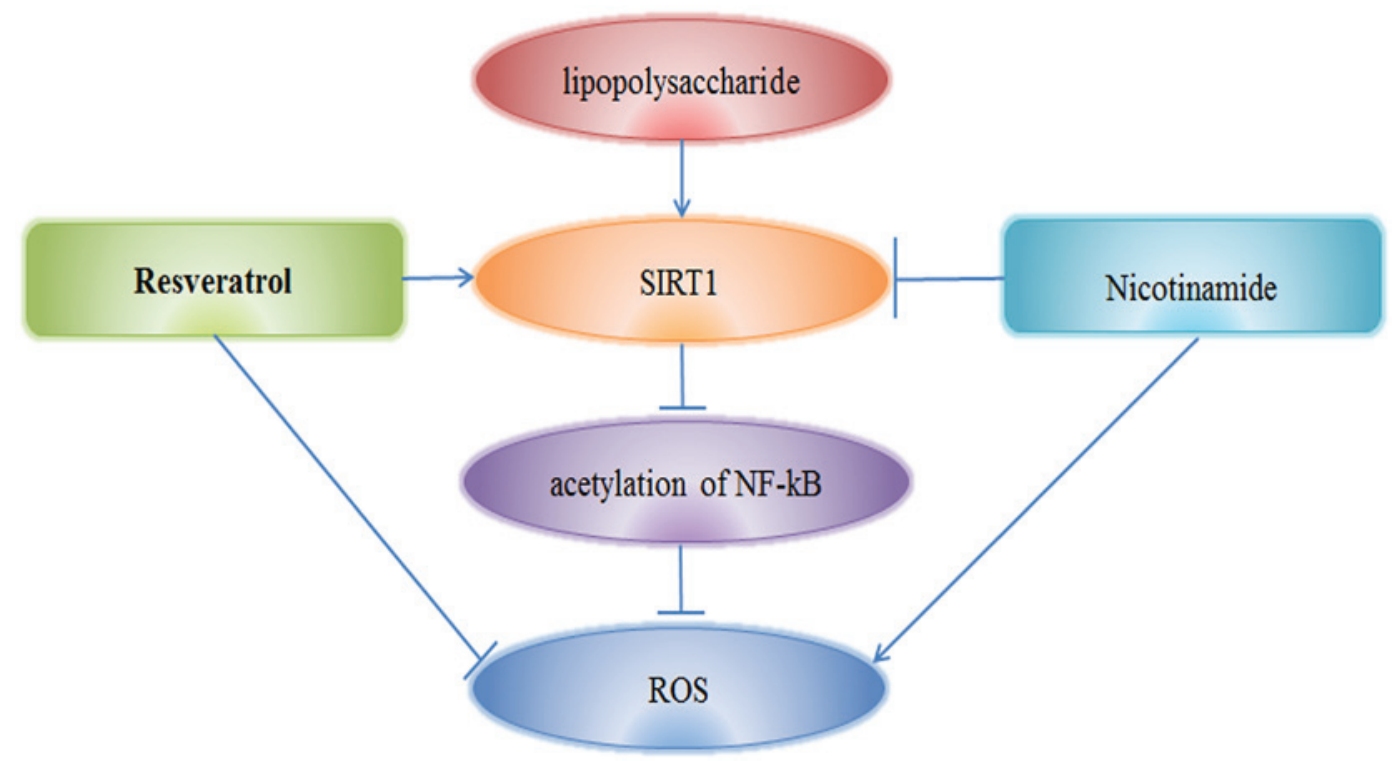

Figure 5. Lipopolysaccharides can increase ROS generation in A549 cells. SIRT1 serves an important role in regulating human alveolar epithelial A549 cell oxidative stress induced by lipopolysaccharides through NF- $\kappa$ B deacetylation. ROS, reactive oxygen species; SIRT1, sirtuin 1; NF- $\kappa$ B, nuclear factor $\kappa B$.

result in functional gain and loss. Res has been previously reported as a widely used activator of SIRT1 $(49,50)$. The current study demonstrates that A549 cell exposure to LPS increases SIRT1 expression. In addition, levels of intracellular ROS were reduced. The current study also hypothesized that the protective effect of Res against LPS-induced A549 cell oxidative stress may be associated with SIRT1 activation and modulation of deacetylation of NF- $\mathrm{BB}$; and this was verified by western blotting analysis of SIRT1, NF- $\kappa \mathrm{B}$ and acetylated NF- $\kappa \mathrm{B}$. To further verify the above hypothesis, NAM was utilized as a SIRT1 inhibitor to examine the role of SIRT1 regulation in LPS-induced A549 oxidative stress. The results demonstrated that treatment of A549 cells with NAM reduced SIRT1 protein expression in the A549 cells in a dose-dependent manner. The A549 cell oxidative stress induced by LPS was aggravated by NAM, and ROS generation was increased in the A549 cells. The effects of LPS on SIRT1 pathway inhibition were aggravated by NAM in the A549 cells. Taken together, these results indicate the central and pivotal role of SIRT1 in LPS-induced oxidative stress in A549 cells via modulation of the NF- $\kappa$ B pathway, which maybe a potential translational target for treating $P$. aeruginosa pneumonia.

In conclusion, the results of the current study suggest that A549 cell oxidative stress is induced by LPS. SIRT1 serves a central role in the oxidative stress induced by LPS through inducing NF- $\mathrm{NB}$ deacetylation. Res defends against LPS-induced A549 cell oxidative stress via activation of SIRT1 and NAM aggravates the A549 cell oxidative stress induced by LPS. SIRT1 activators are suggested as a promising therapeutic interventional target for $P$. aeruginosa infections.

\section{Acknowledgements}

The present study was supported by the National Natural Science Foundation of China (grant no. 81270495).

\section{References}

1. Quartin AA, Scerpella EG, Puttagunta S and Kett DH: A comparison of microbiology and demographics among patients with healthcare-associated, hospital-acquired and ventilator-associated pneumonia: A retrospective analysis of 1184 patients from a large, international study. BMC Infect Dis 13: 561, 2013.

2. Restrepo MI and Anzueto A: The role of gram-negative bacteria in healthcare-associated pneumonia. Semin Respir Crit Care Med 30: 61-66, 2009.

3. Zilberberg MD and Shorr AF: Epidemiology of healthcare-associated pneumonia (HCAP). Semin Respir Crit Care Med 30: 10-15, 2009.

4. Di Pasquale M, Ferrer M, Esperatti M, Crisafulli E, Giunta V, Li Bassi G, Rinaudo M, Blasi F, Niederman M and Torres A: Assessment of severity of ICU-acquired pneumonia and association with etiology. Crit Care Med 42: 303-312, 2014.

5. Sadikot RT, Blackwell TS, Christman JW and Prince AS: Pathogen-host interactions in Pseudomonas aeruginosa pneumonia. Am J Respir Crit Care Med 171: 1209-1223, 2005.

6. Ramos GP, Rocha JL and Tuon FF: Seasonal humidity may influence Pseudomonas aeruginosa hospital-acquired infection rates. Int J Infect Dis 17: e757-e761, 2013.

7. Gaynes R and Edwards JR; National Nosocomial Infections Surveillance System: Overview of nosocomial infections caused by gram-negative bacilli. Clin Infect Dis 41: 848-854, 2005.

8. Rello J, Ollendorf DA, Oster G, Vera-Llonch M, Bellm L, Redman R and Kollef MH; VAP Outcomes Scientific Advisory Group: Epidemiology and outcomes of ventilator-associated pneumonia in a large US database. Chest 122: 2115-2121, 2002.

9. Fang GD, Fine M, Orloff J, Arisumi D, Yu VL, Kapoor W, Grayston JT, Wang SP, Kohler R and Muder RR: New and emerging etiologies for community-acquired pneumonia with implications for therapy. A prospective multicenter study of 359 cases. Medicine (Baltimore) 69: 307-316, 1990.

10. Blanquer J, Blanquer R, Borrás R, Nauffal D, Morales P, Menéndez R, Subías I, Herrero L, Redón J and Pascual J: Aetiology of community acquired pneumonia in Valencia, Spain: A multicentre prospective study. Thorax 46: 508-511, 1991.

11. Neill AM, Martin IR, Weir R, Anderson R, Chereshsky A, Epton MJ, Jackson R, Schousboe M, Frampton C, Hutton S, et al: Community acquired pneumonia: Aetiology and usefulness of severity criteria on admission. Thorax 51: 1010-1016, 1996.

12. Crapo JD, Barry BE, Gehr P, Bachofen M and Weibel ER: Cell number and cell characteristics of the normal human lung. Am Rev Respir Dis 126: 332-337, 1982. 
13. Herzog EL, Brody AR, Colby TV, Mason R and Williams MC: Knowns and unknowns of the alveolus. Proc Am Thorac Soc 5: 778-782, 2008

14. Perlman CE and Bhattacharya J: Alveolar expansion imaged by optical sectioning microscopy. J Appl Physiol (1985) 103 1037-1044, 2007.

15. Imai S, Armstrong CM, Kaeberlein M and Guarente L: Transcriptional silencing and longevity protein Sir2 is an NAD-dependent histone deacetylase. Nature 403: 795-800, 2000.

16. Chung S, Yao H, Caito S, Hwang JW, Arunachalam G and Rahman I: Regulation of SIRT1 in cellular functions: Role of polyphenols. Arch Biochem Biophys 501: 79-90, 2010.

17. Rahman I, Kinnula VL, Gorbunova V and Yao H: SIRT1 as a therapeutic target in inflammaging of the pulmonary disease. Prev Med 54 (Suppl): S20-S28, 2012.

18. Yao $\mathrm{H}$ and Rahman I: Perspectives on translational and therapeutic aspects of SIRT1 in inflammaging and senescence. Biochem Pharmacol 84: 1332-1339, 2012.

19. Yao H, Chung S, Hwang JW, Rajendrasozhan S, Sundar IK Dean DA, McBurney MW, Guarente L, Gu W, Rönty M, et al: SIRT1 protects against emphysema via FOXO3-mediated reduction of premature senescence in mice. J Clin Invest 122: 2032-2045, 2012.

20. Dey N, Chattopadhyay DJ and Chatterjee IB: Molecular mechanisms of cigarette smoke-induced proliferation of lung cells and prevention by vitamin C. J Oncol 2011: 561862, 2011.

21. Kume S, Haneda M, Kanasaki K, Sugimoto T, Araki S, Isono M, Isshiki K, Uzu T, Kashiwagi A and Koya D: Silent information regulator 2 (SIRT1) attenuates oxidative stress-induced mesangial cell apoptosis via p53 deacetylation. Free Radic Biol Med 40: 2175-2182, 2006.

22. Chua KF, Mostoslavsky R, Lombard DB, Pang WW, Saito S, Franco S, Kaushal D, Cheng HL, Fischer MR, Stokes N, et al: Mammalian SIRT1 limits replicative life span in response to chronic genotoxic stress. Cell Metab 2: 67-76, 2005.

23. Li Y, Xu W, McBurney MW and Longo VD: SirT1 inhibition reduces IGF-I/IRS-2/Ras/ERK1/2 signaling and protects neurons. Cell Metab 8: 38-48, 2008.

24. Hah YS, Cheon YH, Lim HS, Cho HY, Park BH, Ka SO, Lee YR, Jeong DW, Kim HO, Han MK and Lee SI: Myeloid deletion of SIRT1 aggravates serum transfer arthritis in mice via nuclear factor- $\kappa \mathrm{B}$ activation. PLoS One 9: e87733, 2014.

25. Yang $T$, Chen $M$ and Sun $T$ : Simvastatin attenuates TGF- $\beta 1$-induced epithelial-mesenchymal transition in human alveolar epithelial cells. Cell Physiol Biochem 31: 863-874, 2013

26. Hsieh TC, Wu ST, Bennett DJ, Doonan BB, Wu E and Wu JM Functional/activity network (FAN) analysis of gene-phenotype connectivity liaised by grape polyphenol resveratrol. Oncotarget 7: 38670-38680, 2016.

27. Blanquer-Rosselló MD, Hernández-López R, Roca P, Oliver J and Valle A: Resveratrol induces mitochondrial respiration and apoptosis in SW620 colon cancer cells. Biochim Biophys Acta: Oct 17, 2016 (Epub ahead of print).

28. Caddeo C, Nacher A, Vassallo A, Armentano MF, Pons R, Fernàndez-Busquets $\mathrm{X}$, Carbone $\mathrm{C}$, Valenti $\mathrm{D}$, Fadda $\mathrm{AM}$ and Manconi M: Effect of quercetin and resveratrol co-incorporated in liposomes against inflammatory/oxidative response associated with skin cancer. Int J Pharm 513: 153-163, 2016.

29. Riveiro-Naveira RR, Valcárcel-Ares MN, Almonte-Becerril M, Vaamonde-García C, Loureiro J, Hermida-Carballo L, López-Peláez E, Blanco FJ and López-Armada MJ: Resveratrol lowers synovial hyperplasia, inflammatory markers and oxidative damage in an acute antigen-induced arthritis model. Rheumatology (Oxford) 55: 1889-9000, 2016.

30. Jeong H, Samdani KJ, Yoo DH, Lee DW, Kim NH, Yoo IS and Lee JH: Resveratrol cross-linked chitosan loaded with phospholipid for controlled release and antioxidant activity. Int J Biol Macromol 93: 757-766, 2016.

31. Tang L, Yang F, Fang Z and Hu C: Resveratrol Ameliorates Alcoholic Fatty Liver by Inducing Autophagy. Am J Chin Med 44: 1207-1220, 2016

32. Arabi Y, Al-Shirawi N, Memish Z and Anzueto A: Ventilator-associated pneumonia in adults in developing countries: A systematic review. Int J Infect Dis 12: 505-512, 2008.
33. Lee MS, Walker V, Chen LF, Sexton DJ and Anderson DJ: The epidemiology of ventilator-associated pneumonia in a network of community hospitals: A prospective multicenter study. Infect Control Hosp Epidemiol 34: 657-662, 2013.

34. Tumbarello M, De Pascale G, Trecarichi EM, Spanu T, Antonicelli F, Maviglia R, Pennisi MA, Bello G and Antonelli M: Clinical outcomes of Pseudomonas aeruginosa pneumonia in intensive care unit patients. Intensive Care Med 39: 682-692, 2013.

35. Chian CF, Chiang CH, Yuan-Jung C, Chuang CH, Liu SL, Yi-Han J, Zhang H and Ryu JH: Apocynin attenuates lipopolysaccharide-induced lung injury in an isolated and perfused rat lung model. Shock 38: 196-202, 2012.

36. Boots AW, Gerloff K, Bartholomé R, van Berlo D, Ledermann K, Haenen GR, Bast A, van Schooten FJ, Albrecht C and Schins RP: Neutrophils augment LPS-mediated pro-inflammatory signaling in human lung epithelial cells. Biochim Biophys Acta 1823: $1151-1162,2012$.

37. Cho RL, Yang CC, Lee IT, Lin CC, Chi PL, Hsiao LD and Yang CM: Lipopolysaccharide induces ICAM-1 expression via a c-Src/NADPH oxidase/ROS-dependent NF- $\kappa \mathrm{B}$ pathway in human pulmonary alveolar epithelial cells. Am J Physiol Lung Cell Mol Physiol 310: L639-L657, 2016.

38. Kinoshita M, Sanuki T, Yamada Y, Sasaki A, Yoshie T, Kuroda D, Kanzawa M and Itou T: A case of esophageal mucosa-associated lymphoid tissue lymphoma diagnosed using endoscopic ultrasound-guided fine-needle aspiration. Nihon Shokakibyo Gakkai Zasshi 113: 63-70, 2016.

39. Yang L, Li D, Zhuo Y, Zhang S, Wang X and Gao H: Protective Role of Liriodendrin in Sepsis-Induced Acute Lung Injury. Inflammation 39: 1805-1813, 2016.

40. Liu X, Pei C, Yan S, Liu G, Liu G, Chen W, Cui Y and Liu Y: NADPH oxidase 1-dependent ROS is crucial for TLR4 signaling to promote tumor metastasis of non-small cell lung cancer. Tumour Biol 36: 1493-1502, 2015.

41. Yamamoto H, Schoonjans K and Auwerx J: Sirtuin functions in health and disease. Mol Endocrinol 21: 1745-1755, 2007.

42. Kong XX, Wang R, Liu XJ, Zhu LL, Shao D, Chang YS and Fang FD: Function of SIRT1 in physiology. Biochemistry (Mosc) 74: 703-708, 2009.

43. Hwang JW, Sundar IK, Yao H, Sellix MT and Rahman I: Circadian clock function is disrupted by environmental tobacco/cigarette smoke, leading to lung inflammation and injury via a SIRT1-BMAL1 pathway. FASEB J 28: 176-194, 2014.

44. Guo H, Chen Y, Liao L and Wu W: Resveratrol protects HUVECs from oxidized-LDL induced oxidative damage by autophagy upregulation via the AMPK/SIRT1 pathway. Cardiovasc Drugs Ther 27: 189-198, 2013

45. Hu YX, Cui H, Fan L, Pan XJ, Wu JH, Shi SZ, Cui SY, Wei ZM and Liu L: Resveratrol attenuates left ventricular remodeling in old rats with COPD induced by cigarette smoke exposure and LPS instillation. Can J Physiol Pharmacol 91: 1044-1054, 2013.

46. Yang Y, Duan W, Lin Y, Yi W, Liang Z, Yan J, Wang N, Deng C, Zhang S, Li Y, et al: SIRT1 activation by curcumin pretreatment attenuates mitochondrial oxidative damage induced by myocardial ischemia reperfusion injury. Free Radic Biol Med 65: 667-679, 2013.

47. Lim HD, Kim YS, Ko SH, Yoon IJ, Cho SG, Chun YH, Choi BJ and Kim EC: Cytoprotective and anti-inflammatory effects of melatonin in hydrogen peroxide-stimulated CHON-001 human chondrocyte cell line and rabbit model of osteoarthritis via the SIRT1 pathway. J Pineal Res 53: 225-237, 2012.

48. Brandl A, Meyer M, Bechmann V, Nerlich M and Angele P. Oxidative stress induces senescence in human mesenchymal stem cells. Exp Cell Res 317: 1541-1547, 2011.

49. Howitz KT, Bitterman KJ, Cohen HY, Lamming DW, Lavu S, Wood JG, Zipkin RE, Chung P, Kisielewski A, Zhang LL, et al: Small molecule activators of sirtuins extend Saccharomyces cerevisiae lifespan. Nature 425: 191-196, 2003

50. Wood JG, Rogina B, Lavu S, Howitz K, Helfand SL, Tatar M and Sinclair D: Sirtuin activators mimic caloric restriction and delay ageing in metazoans. Nature 430: 686-689, 2004. 